\title{
The Legal Critical Literature Review
}

\author{
Md. Nuruddeen
}

\begin{abstract}
This paper explains the legal critical literature review in the critical context of the logic of scholarship. The paper asks what makes a critical literature review effective in research. It suggests that critical literature reviews are effective in research when they more easily allow the identification of research gaps, in the specified context. The methodology employs cumulative synthesis from the relevant materials, following Bentham's ideas on synthesis, that analysis opposes both generalization and synthesis. The paper begins its argument by outlining the nature of a critical literature review. Then, it proceeds with a review of key terms required by the writer. Following this essential background, the paper discusses literature gaps and literature search methodologies. Then it moves on to the ideal format of a critical literature review. Finally, argument deals with the purpose of a critical literature review and techniques for writing the critical literature review. A legal critical literature review will be maximally effective when it sets a correct context for research, identifies fallacies in the scholarship in order to discover research gaps, and then forms this outcome into a central research question.
\end{abstract}

Keywords: legal critical literature review, research gaps, fallacies, research question.

\section{Introduction}

This paper is significant because it explains the critical literature review in the critical context of the logic of scholarship. The object of the paper is to brief the reader on how to construct a critical literature review, especially so that it can facilitate quality legal research. ${ }^{1}$ The paper asks what makes a critical literature review effective in research. It suggests that critical literature reviews are effective in research when they more easily allow the identification of research gaps.

The methodology of this paper is to aid researchers in an enhanced understanding of identifying research gaps by using synthesis from the relevant materials, following Bentham's ideas on synthesis in context with analysis and generalization. ${ }^{2}$ Ogden stated, collating Bentham's views from his Theory of Fictions that analysis opposed both generalization and synthesis. Generalization is the converse of analysis. ${ }^{3}$

For the purpose of clarity, the paper begins its argument by outlining the nature of a critical literature review, to provide the reader with a firm definitional foundation. Then, the argument proceeds with a review of key terms required by the writer. These terms are rarely discussed and put into a historical, rhetorical context. Here, they are defined and described so the reader can rely on them. Following this essential background, the paper

\footnotetext{
${ }^{1}$ The literature review is the part of the thesis where there is an extensive reference to related research and theory in a particular field of study. It is an opportunity for a researcher to engage in a written dialogue with other researchers. The researcher must show that has engaged with, understood and responded to the relevant body of knowledge underpinning his research. Thereby embedding his contributions to the body of the existing literature. The literature review identifies the theories and previous research which influence the researcher to choose his research topic and the methodology to be adopted for his research. In short, there are five fundamental identified key terms involved an effective literature review viz: the thesis, research, theory, knowledge, and gap. Thses terms would explained in detail in the preceding part of this paper.D Ridley, The literature review - A Step-by-Step guide for students, Sage, London, 2008, p. 1.

${ }^{2}$ CK Ogden, Bentham's Theory of Fictions, Routledge, New York, 2001, pp. 1xxiii-lxxiv.

${ }^{3}$ Generalization is formed by setting out all the views of many sources and by finding a property that is a common link between them, which bonds them together. This common property is a generalization. By dividing up this property into its constituent parts, the analysis is formed. Synthesis and analysis are opposites, but generalization and synthesis are not exactly synonymous. Synthesis is the putting together of ideas, no matter how heterogeneous they might be. Thus, synthesis is only opposite to analysis when it produces a generalization. Ogden.
} 
discusses literature gaps and literature search methodologies. Then it moves on to the ideal format of a critical literature review. Finally, argument deals with the purpose of a critical literature review, and also, techniques for writing the legal critical literature review.

The outcome of this investigation is likely to suggest that a legal critical literature review will be maximally effective when it sets a correct context for research, and also, when itidentifies fallacies in the scholarship to discover research gaps. It then forms this outcome into a central research question, a thesis statement that answers this question, and research objectives designed to structure the ensuing substantive research.

\section{Outlining a Critical Literature Review}

A critical literature review ${ }^{4}$ positions a research within the larger academic context because it has connections with the work of others. Thus, because it is an essential structural element of the research, its architecture must be thoughtfully planned from the beginning. ${ }^{5}$ The critical literature review deals with information ${ }^{6}$ evaluation and synthesis mainly focusing on observations and drawing conclusions from them. ${ }^{7}$ In short, it is an objective, thorough summary and critical analysis of the relevant available literature on the topic being studied. ${ }^{8}$

Ridley argued a working description of a critical literature review as follows:

The literature review is the part of the thesis where there is an extensive reference to related research and theory in your field. It is where connections are made between the source texts that you draw on and when you position yourself and your research among their sources. It is your opportunity to engage in a written dialogue with researchers in your area while at the same time showing that you have engaged with, understood and responded to the relevant body of knowledge underpinning your research. The literature review is where you identify the theories and previous research which have influenced your choice of research topic and the methodology you are choosing to adopt. You can use the literature to support your identification of a problem to research and to illustrate that there is a gap in previous research, which needs to be filled. The literature review, therefore, serves as the driving force and jumping-off point for your research investigation. ${ }^{9}$

An effective critical literature review has a necessary connection withits academic field. It involves written dialogue with other researchers. ${ }^{10}$ It is purely conducted for and supported by the works of academicians who published their materials in the relevant area of a prospective researcher. ${ }^{11}$ One of the qualities of a good critical literature review is to gather information about a particular subject from many sources. ${ }^{12}$ Thus, a critical literature review would be considered to have created a firmer foundation for the advancementof knowledge. It would facilitate theory development, critique areas where a plethora of research existed and uncovere areas

\footnotetext{
${ }^{4}$ Critical here refers to the constructive approach in appraising the literature. B Steward, 'Writing a literature review', Br J Occup Ther 67, 2004, pp. 495-500.

${ }^{5}$ Ridley, p. 1.

${ }^{6}$ Information is a transmitted message of human experiences, a signal, stimulus and symbol or set of symbols, which has the potential for meaning, essentially denoting removal of doubt. It is also defined as a knowledge communicated or received on a particular subject, phenomena or event. M Nuruddeen, 'Legal and human rights issues in Freedom of Information Act 2011', Human Rights Review, vol. 2, 2012, pp. 171-190.

${ }^{7}$ RJ Justus 'A guide to writing the dissertation literature review', Practical Assessment, Research and Evaluation, vol. 14, no. 13, 2009, p. 2.

${ }^{8}$ C Hart, Doing a literature review, Sage Publications, London, 1998.

${ }^{9}$ Ridley, p. 2.

${ }^{10}$ WL Neuman, Social research methods: qualitative and quantitative approaches, 5 th edn, Pearson Education Inc., Boston, 2003, p. 96.

${ }^{11}$ Z O'Leary, Researching real-world problems: a guide to methods inquiry, Sage Publications Ltd., London, 2005, pp. 45-47.

${ }^{12}$ C Patricia, F Ryan \& M Coughlan, 'Undertaking a literature review: a step-by-step approach', British Journal of Nursing, vol. 17, no.1, 2008, p. 40.
} 
where research is needed. ${ }^{13}$ Those who have made substantial progress in a particular stream of research are better positioned to tell others what they have learned, and where the field can most fruitfully direct its attention, ${ }^{14}$ suggesting the significance of a critical literature review of research work.

Literature reviews are found in many places and are written for many reasons. ${ }^{15}$ For instance, literature reviews are found in proposals for funding and for academic degrees, in research articles, in guidelines for professional and evidence-based practices, and in reports to satisfy personal curiosity. ${ }^{16}$ However, this paper explains the concept of literature reviews within the critical context of legal scholarship.

\section{The Fundamental Elements in a Critical Literature Review}

Having set out the critical literature review's essential elements,in Ridley's description as above. It is necessary to examine critically, the five fundamental key terms contained in her description, namely: thesis, research, theory, knowledge, and gap. On this basis can be developed the elements of effectiveness for a legal critical literature review. They are as follows:

\section{Thesis}

The literature review is the part of the thesis ${ }^{17}$ where the researcher provides an extensive reference to related research and theories in his area. ${ }^{18}$ Athesis means defense or refutation ${ }^{19}$ of a proposition. ${ }^{20}$ It is the main idea of an essay, report, speech, or research paper, sometimes written as a single declarative sentence known as a thesis statement. A thesis statement is a main ideaof writing a thesis. It contains a single idea, a clear focus and is specifically stated, which grows out of the exploration of a particular research problem. It is expressed in the form of an assertion or claim statement that indicates what a researcher claims to be true or paramount to his research. $^{21}$

In some cases, the thesis statement may be stated in more than one sentence, often stated in a declarative sentence with a single main clause, ${ }^{22}$ that is, in either a simple or a complex sentence. ${ }^{23}$ For example, if a researcher intends to sharpen the thesis statement, by adding informationthat qualifies or supports it, he or she should subordinate such information to the main idea, so that the thesis will not lose it's focus and direction. ${ }^{24}$

Advantages of a thesis statement in effective critical literature reviews and other kinds of academic and nonacademic writings abound. It helps a researcher to remain focused throughout the research. It also brings to

\footnotetext{
${ }^{13} \mathrm{~J}$ Webster \& RT Watson, 'Analyzing the past to prepare for the future: writing a literature review', MIS Quarterly, vol. 26, no. 2, June 2002,pp. xiii-xxiii, p xiii.

${ }^{14}$ Webster \& Watson.

${ }^{15}$ A Bolderston, 'Writing an effective literature review', Journal of Medical Imaging and Radiation Sciences, vol. 39,2008 , pp. $86-92$.

${ }^{16}$ A Fink, Conducting research literature reviews: from the internet to paper, 2nd edn, Sage Publications, Thousand Oaks, Canada, 2004, pp. 20.

${ }^{17}$ Literature reviews are also found in proposals for funding, in research articles, in guidelines for professional and evidence-based practices, and in reports to satisfy personal curiosity. Fink.

${ }^{18}$ Ridley, p. 2.

${ }^{19}$ Refutation is the part of an argument in which a speaker or writer counters opposing points of view. EPJ Corbett \& RJ Connors, Classical Rhetoric for the modern students, 4th edn, Oxford University Press New York, 1999, p. 484.

${ }^{20}$ GA Kennedy, Progymnasmata - Greek textbooks of Prose Composition and Rhetoric, Society of Biblical Literature, Atlanta, USA, 2003, pp. 55-56.

${ }^{21}$ JC Hodges, ST Web \& RK Miller, Harbrace College handbook, 12th edn, Harcourt Brace College Publishers, USA, 1994, pp. 362-365.

${ }^{22}$ Hodges, Web \& Miller.

${ }^{23}$ Hodges, Web \& Miller.

${ }^{24}$ Hodges, Web \& Miller.
} 
light what a researcher is writing about and what approach is being taken, and in some cases the plan of development being used. ${ }^{25}$

A clear, precise thesis statement will help a researcher unify the research. For instance, while carrying out a critical literature review, a thesis statement will guide many decisions about what details to keep and what to discard. In fact, a thesis statement could be used to search for additional information that one may need to strengthen a point. ${ }^{26} \mathrm{~A}$ thesis statement can appear either in the introductory section or anywhere in the main body of the research or even in the conclusion. ${ }^{27}$ But it will be more advantageous if a researcher puts it in the introductory section. Here, the reader knows from the beginning what the author is writing about and the central focus of the research. ${ }^{28}$

A researcher should develop a thesis statement out of his thinking and discovery processes. ${ }^{29}$ However, the goal should be a claim that is neither self-evident nor too broad or too specific to interest a reader. ${ }^{30}$ At regular intervals, a researcher should check whatever he writes, to ensure conformity with the main idea of the thesis statement. He should not hesitate to change his thesis statement if he discovers a more productive path.Particularly, when arriving at the revision stage, heshould test everything writtenagainst the thesis statement, and should carefully discard or otherwise note any information that is contrary to it. ${ }^{31}$ Doing this will ensure a unified essay or thesis. ${ }^{32}$

A researcher should avoid vague qualifiers ${ }^{33}$ while writing a thesis statement. ${ }^{34}$ For example in a thesis statement "my education has been very unusual", the vague word here is "unusual", which may indicate that the idea itself is trivial and unproductive and that the researcher needs to find a more appropriate subject. ${ }^{35}$

However, sometimes thesis statements containing vague qualifiers can be made more effective by simply replacing the bland words with other more meaningful ones. ${ }^{36}$ A vague thesis statement such as "I have trouble making decisions" and "Summer is an interesting season" can be replaced with more focused and clarified ones.These could be amended to "making decisions is difficult for me, especially when money is involved and most of all when such decisions affect other people" and "summer is the best season for losing weight" respectively. ${ }^{37}$

In another sense, a thesis is a whole work in an ancient form. It is an intellectual piece of original work based on research or study conducted for the purposes of obtaining an advanced academic degree in a particular field of study. ${ }^{38}$ The English Renaissance period saw a humanist introduction of new educational curricula,

\footnotetext{
${ }^{25}$ Hodges, Web \& Miller.

${ }^{26}$ Hodges, Web \& Miller, pp. 362-365.

${ }^{27}$ It is just a matter of style. A researcher can choose the one that fits his study.

${ }^{28}$ Hodges, Web \& Miller.

${ }^{29}$ The research should frame the thesis statement using his good initiatives.

${ }^{30}$ Hodges, Web \& Miller, pp. 362-365.

${ }^{31}$ Hodges, Web \& Miller.

${ }^{32}$ Hodges, Web \& Miller.

${ }^{33}$ Vague qualifiers are words that meant to strengthen an expression, such as 'interesting', 'unusual', 'very,' 'extremely,' 'totally,' 'entirely,' 'utterly,' 'really,' or 'completely.' Or words that diminish, such as 'somewhat,' 'rather,' 'slightly,' 'quite,' and so forth. Such qualifiers are valuable in speech. They help us get closer to our meaning when we cannot think of the perfect word. The most interesting and paradoxical thing about those qualifiers intended to strengthen is that they actually weaken. So cutting qualifiers creates a curious and welcome effect: The word left standing becomes stronger and more assertive in its solitude. P LaRocque, 'Vague Qualifiers' - A Commentary', KERA News, 2015, retrieved 9 June 2015, <http://keranews.org/post/vaguequalifiers-commentary $>$.

${ }^{34}$ Hodges, Web \& Miller.

${ }^{35}$ Hodges, Web \& Miller.

${ }^{36}$ Hodges, Web \& Miller.

${ }^{37}$ Hodges, Web \& Miller.

${ }^{38}$ NM Noor, Writing research and thesis proposals: guide lines and examples, Penerbit Press (UiTM), Malaysia, 2012, pp. 2-3.
} 
concentrating again on ancient sophistical teachings. For example, according to Van der Poel, students would learn their way through and master the sophistical progymnasmata, ${ }^{39}$ andthen begin the practice of declamation, ${ }^{40}$ at the pinnacle of their rhetorical skill. ${ }^{41}$ Van der Poel stated that the ancient didactic declamation and the humanist form of the declamation were linkedby Cicero's rhetorical exercise of the thesis. ${ }^{42}$ The thesis was originally a philosophical and dialectic exercise mainly in the a priori pre-legal field of ethics, from which could arise arguments about negligence, negligence being about a de facto moral or ethical state of affairs. The exercise would argue pros and cons theoretically without reference to a given person, time, or place. Cicero's modification to this format had been to interweave concrete circumstances involving persons, places and times, (hypotheses) so as to make the exercise into one of better utility in legal pleadings and public orations. ${ }^{43}$

Thus, according to the context of the ancient Greek sophistical progymnasmata, the thesis was an exercise that required a student to argue a case for one side or the other. ${ }^{44}$ For the purpose of clarity, the progymnasmata ${ }^{45}$ were a series of exercises that introduced students to basic rhetorical concepts and strategies. ${ }^{46}$ The progymnasmata consisted of a gradated sequence of rhetorical assignments, ${ }^{47}$ in which students were asked to perform, as they became more mature and experienced. They were developed over 2,000 years ago in ancient Greece and Rome. ${ }^{48}$ Traditionally, the progymnasmata contained 14 assignments or exercises ranked by the degree of complexity, rising cognitive demands, and increasing range of cultural knowledge. ${ }^{49}$ Younger children practiced the early exercises as part of the essential language arts curriculum. Older students engaged in the later assignments in courses on rhetoric. ${ }^{50}$

The assignments or exercises, as stated above, were in ascending order of complexity: fable ${ }^{51}$ narrative, ${ }^{52}$ anecdote, ${ }^{53}$ proverb ${ }^{54}$ refutation, ${ }^{55}$ confirmation, ${ }^{56}$ commonplace, ${ }^{57}$ encomium, ${ }^{58}$ invective, ${ }^{59}$ comparison, ${ }^{60}$

\footnotetext{
${ }^{39}$ Progymnasmata. Oratorical exercises, arranged from the simplest to the most complex and difficult. There were several versions of the progymnasmata, devised by various ancient sophistical scholars. In most versions, the chriea was characterized as the most basic element. The second most difficult was the thesis and the most complicated lesson was the highest oratorical exercise on the progymnasmata scale: "make a law". George Kennedy catalogued the various schools of progymnasmata lessons in ancient classical rhetoric. Kennedy, p. 97. ${ }^{40}$ Also called declamation. The declamation are two, the lesser and the Greater. The declamations dating back perhaps from the second century A.D. and attributed to Quintilian, might more accurately be described as emanating from the " the school of Quintilian". They are one of the collections of teaching technique surviving Greek and Latin. Higher education in Rome was an education in rhetoric, the art and practice of verbal persuasion, and the prime didactic was the academic declamation. The Declamation now are composed of specimen speeches for fictitious court cases with comments and suggestions concerning presentation and arguing tactics. Thereby giving a reader an insight into the Roman law and education. DRS Bailey, the Lesser Declamations, vol. 1, Harvard University Press, England, 2006, pp. 1-4.

${ }^{41}$ MV Poel, 'The Latin Declamatio in Renaissance Humanism,' The Sixteenth Century Journal, vol. 20 no. 3 , 1989, pp. 471-478. And see below for an example of argument in declamatory form.

${ }^{42}$ Poel.

${ }^{43}$ Poel.

${ }^{44}$ N Richard, Thesis (composition), About Education, 2015, retrieved 22 March $2015,<$ http://grammar.about.com/od/tz/g/thesis.htm>.

${ }^{45}$ Kennedy, pp. x-xi.

${ }^{46} \mathrm{~N}$ Richard, What are Progymnasmata? Classical Rhetorical exercises for today's writers, About Education, 2015, retrieved 28 March 2015, <http://grammar.about.com/od/qaaboutrhetoric/f/fqprogymnasmata.htm>.

${ }^{47}$ Richard.

${ }^{48}$ Richard.

${ }^{49}$ Richard.

${ }^{50}$ Richard.

${ }^{51}$ Fable here means a fictional narrative meant to teach a moral lesson or retelling of a folk tale. Corbett \& Connors.

${ }^{52}$ Narrative is an account of a sequence of events, usually in chronological order. Narrative can be either fiction or nonfiction (Corbett \& Connors). Narrative is also defined as an exposition of events that have happened or that are supposed to have happened (FJ D'angelo, Composition in the Classical Tradition, Allyn \& Bacon, USA, 2000, pp.22-37).

${ }^{53}$ Anecdote is a story based on amplification of a famous statement or action. Corbett \& Connors.
} 
characterization, ${ }^{61}$ description, ${ }^{62}$ thesis, ${ }^{63}$ and defend/attack law (deliberation) ${ }^{64}$ For example, students explored the progymnasmata exercise of deliberation (legislation) to argue for or against the goodness of a law, ${ }^{65}$ or even to construct and propose the public enactment of a law.

The progymnasmata were carefully sequenced. They began with mereparaphrases and ended with sophistical exercises in deliberative and forensic, also known as judicial,rhetoric. Each successive exercise used a skill practiced in the preceding one, but each added some new and more difficult composing task. ${ }^{66}$ In fact, theprogymnasmata fitted into the scheme of thesis writing. Here, the preliminary exercises or assignments were devised to build up students' writing skills. By exposing them to carefully graded drills and composition, ${ }^{67}$ so that each exercise provided some of the underlying elements and skills of the thesis.

The most important thing that students learned by working through the progymnasmata was a set of practices and skills, that could be put to use in the composition of full-scale public speeches or other types of rhetoricalstructure ${ }^{68}$ For example, the progymnasmata exposeda student to arguing a case for one side or the other. ${ }^{69}$ The progymnasmata also taught students to consider issues of comparison, such as examining the similarities and differences between two people, places, ideas, or things, to explore their comparative merits and shortcomings. ${ }^{70}$

This is now the practice in modern research, especially in the social sciences. ${ }^{71}$ Sampling and measurement are now some of the techniques used in modern research to achieve this purpose. ${ }^{72}$ Sampling is the process of selecting units (e.g., people or organization) from a population of interest.So that by studying the sample one may fairly generalize one's result back to the population from which they were chosen. ${ }^{73}$ In legal research, the sample might be the evidence of the scholarly argument. Measurement is the process of observing and recording

${ }^{54}$ Proverb is a short sentence based on long experience.eg, "Out of sight, out of mind," "Penny wise, pound foolish," "A bird in the hand is worth two in the bush." Etc. proverb is normally done by students to amplify by arguing for or against some maxim o adage. Corbett \& Connors.

${ }^{55}$ Refutation is the part of an argument in which a speaker or writer counters opposing points of view. Corbett \& Connors.

${ }^{56}$ Confirmation in classical rhetoric is the main part of a speech or text in which logical arguments in support of a position (or claim) are elaborated. In fact confirmation proved the persuasive point of a narrative. Corbett \& Connors.

${ }^{57}$ Commonplace is a statement or bit of knowledge that is commonly shared by members of an audience or a community. Corbett \& Connors.

${ }^{58}$ Encomium is a formal expression of praise. An encomium is a tribute or eulogy in prose or verse honoring a person, an idea, a thing, or an event. Corbett \& Connors.

${ }^{59}$ Invective is an abusive language or a discourse that casts blame on somebody or something. Corbett \& Connors.

${ }^{60}$ Comparison is a rhetorical strategy and method of organization in which a writer examines similarities and/or differences between two people, places, ideas, or things to explore their comparative merits and shortcomings.

Corbett \& Connors, p. 485.

${ }^{61}$ Characterization or personification in classical rhetoric means putting oneself in the place of another so as to both understand and express his or her feelings more vividly. Corbett \& Connors, p. 485.

${ }^{62}$ Description creates an intense and graphic depiction of a subject. Corbett \& Connors, p. 485.

${ }^{63}$ Corbett \& Connors, p. 485.

${ }^{64}$ Corbett \& Connors, p. 485.

${ }^{65}$ Corbett \& Connors, p. 485.

${ }^{66}$ Richard.

${ }^{67}$ S Nervegna, Menander in Antiquity: The contexts of reception, Cambridge University Press, 2013, p. 212.

${ }^{68}$ Richard, Thesis (composition).

${ }^{69}$ Nervegna.

${ }^{70}$ Corbett \& Connors, p. 485.

${ }^{71}$ WM Trochim, Foundations, Research Methods Knowledge Base, 2006, retrieved 24 March 2015, $<$ http://www.socialresearchmethods.net/kb/intres.php $>$.

${ }^{72}$ Richard, What are Progymnasmata? Classical Rhetorical Exercises for Today's Writers.

${ }^{73}$ Trochim. 
the observation collected as part of a research effort. ${ }^{74}$ In legal research, a measurement might be critically assessing scholarly arguments.

In social research, there are four broad categories of measurements, depending on the type of research one is undertaking. First, there is survey research that includes the design and implementation of interviews and questionnaires. Second, there is scaling research that involves consideration of the major methods of developing and implementing a scale. Third, there is also qualitative research that provides an overview of the broad range of non-numerical measurement approaches in research. And last, there is unobtrusive measures research that represents a variety of measurement methods that do not intrude on or interfere with the context of the research.$^{75}$ In legal research, the latter two methods are essential to development of the thesis.

Progymnasmata exercises have a connection withthe critical literature review. One similarity between the progymnasmata and the critical literature review is that both of them use narrative methodologies. The narrative is an exposition of events that have happened or that are supposed to have happened. ${ }^{76}$ Narrative serves several purposes in both oral and written arguments. For example, in the service of the poet and that of the historian.It celebrates the past and provides examples of moral behavior for the presentwhile in the service of the rhetorician, the narrative serves the purpose of persuasion. ${ }^{77}$

The narrative can also bean exposition of the facts of an argument to put one's case in the best possible light.It can bean inductive example in the proof part of an argument.So that the speaker or researcher can insert an inducive example in a form of a narrative to demonstrate the truth or probability of a geneal statement or opinion. $^{78}$

In this respect, D'Angelo identified three kinds of narratives: mythical, historical, and legal narratives. The mythical narrative is a story about the gods and heroes that originate in a preliterate society. ${ }^{79}$ Rhetoric draws on myth as a source of inexhaustible examples leading to some moral end. The historical narrative is a chronological record of events in the life and development of people or country. Hence, both myth and history are narratives. But unlike myth, which is a fictitious narrative, history is a factual narrative conducted in real time. Legal narratives, the third kind of narrative, are narratives used in legal cases to present the sequence of events constituting the facts of a case ${ }^{80}$ Mythical and historical narrative can be used in a critical literature review, as a component part of a thesis, to serve as an inductive example in the proof part of an argument. Legal narratives can also be employed in a critical literature review as annex position of the facts of a case in an argument. ${ }^{81}$

A good example of narrative in declamatory form could be found in a short story entitled "Adulteress Killed by Exiled Husband." 82 Here, a man was found guilty of involuntary homicide and was accordingly exiled for five years. One night, before completing his five years punishment, he returned to visit his wife. Unfortunately, he found her committing adultery; he killed her. After completing his term, he was charged with homicide. ${ }^{83}$

He challenged the charge leveled against him, because, the law permitted the killing of adulterers. But the prosecution argued that the law permitting the killing of adulterers caught in the act did not cover the killer because, as an exile, the laws did not apply to him. The killer countered this argument saying that, suppose he (the killer) did return contrary to the law, still he should not be charged with killing but only with having returned illegally.

${ }^{74}$ Trochim.

${ }^{75}$ Trochim.

${ }^{76}$ D'Angelo.

${ }^{77}$ Trochim.

${ }^{78}$ Trochim.

${ }^{79}$ Trochim.

${ }^{80}$ Trochim.

${ }^{81}$ Trochim.

${ }^{82}$ Bailey, pp. 8-13.

${ }^{83}$ Bailey, pp. 8-13. 
The above scenario shows a good example of historical/legal narratives. In that, it shows a narrative sequence of events that led to the trial of the killer, and how the killer and the prosecutor respectively canvassed the arguments. Both of them were trying to be persuasive in support of their arguments respectively.

Thus, thesis writing has a connection with academic writing. Thesis writing requires a student to come up with an essay or report in partial fulfilment for the award of a degree or its equivalent. A thesis must satisfy the guidelines of the awarding institution in terms of format, substance and word limits among other things. ${ }^{84}$ Webster and Watson argued that literature reviews were part of the academic coursework that usually had strictly enforced term limits, and it is important to adhere to that limit. ${ }^{85}$ For example, under the Western Illinois University thesis guidelines, it is clearly spelled out that the format of a thesis should consist of three parts. The preliminaries, text and the references. The guidelines go further and explicitlyexplain what a student is expected to do under each of these three different parts of the thesis. The guidelines also provide elaborate explanations concerning citations and bibliographic entries among other things. ${ }^{86}$ Above all, a thesis should look scholarly, replete with citations of previous researchers. Thus, bridging the gap in the existing literature, building upon new knowledge and reflecting knowledge of the literature cited, and as well showing ability to cite appropriate references. ${ }^{87}$

\section{Research}

The critical literature review identifies previous literature and influences the researcher's decision to conduct a particular piece of research. Hence, research is a studious inquiry or examination, which is aimed at the discovery and interpretation of facts, or revision of accepted theories or laws, in the light of new fact or practical applications of such new or revised theories or laws ${ }^{88}$ Research is the process of gathering data to answer a particular question or questions that can facilitate decision making, thereby aiding problem solution. ${ }^{89}$ It is also considered as an organized, systematic, critical, objective, scientific inquiry or investigation into a specific problem, undertaken with the purpose of finding answers or solutions to it. ${ }^{90}$

The word "research" is a general term used in a variety of ways by different interest groups. These various groups each use the term "research" in a way that reflects their particular philosophical and political perspectives. ${ }^{91}$ In general terms, there are two types of views expressed in the literature about a definition of "research". There is a broad view thattakes into account disciplinary differences and highlights the wide and diverse range of research activities in different settings.Also, there is a narrower view that includes only the discovery of new knowledge, often with an emphasis on quantitative techniques. ${ }^{92}$

Support for the adoption of a broad view comes from the findings of both quantitative and qualitative research studies. ${ }^{93}$ These studies have demonstrated that academics in different fields have different understandings of the term "research". And how research should be conducted, or what its relationship should be to other areas of

\footnotetext{
${ }^{84}$ Patricia, Ryan \& Coughlan.

${ }^{85}$ Webster \& Watson.

${ }^{86}$ Western Illinois, University guidelines for the structure and format of a thesis or applied project, Department of Geography, 2012, retrieved 29 March 2015,

$<$ http://www.wiu.edu/cas/geography/thesis/thesis_guidelines.pdf $>$.

${ }^{87}$ Noor, pp. 9-10.

${ }^{88}$ SC Lynn \& R Ronald, Basic research methods for Librarians', 5th edn, Greenwood Publishing Group, USA, $2010, \mathrm{p} 1$.

${ }^{89}$ O'leary, pp. 3-4.

${ }^{90}$ O'leary, pp. 1-3.

${ }^{91} \mathrm{R}$ Neumann, 'Research and scholarship: perceptions of Senior Academic Administrators', Higher Education, vol. 25, no. 2, March 1993, pp. 97-110.

${ }^{92}$ Neumann.

${ }^{93}$ Neumann.
} 
academic worksuch as in teaching. These studies would suggest that an understanding of "research" is best gained by looking at the context within which the term is used. ${ }^{94}$

Each discipline has its knowledge paradigm that determines the appropriate manner of approaching a research problem. Hence, in some disciplines research is what is done in projects.In sciences, it involves field work or laboratory experimentation. In otherdisciplines such as the law, it is the study of documents in a library. ${ }^{95}$

There is a diversity of activities carried out in different fields under the umbrella of "research" including scholarship, theory construction, observing and chronicling. Other research activities include experiment, theory testing, design, development, criticizing and elucidating, artistic creation, consulting, and advising. Thus, all these activities may be classified as "research",provided they include the discovery of new knowledge or the creation of original art, and also provided that they involve dissemination through publication. This is because, only through dissemination, do they become significant advancementsin knowledge or the arts. ${ }^{96}$

\section{Theory}

The crititical literature review identifies the theories underpinning a particular research. The thoeries may determine the approch to adopt in a particular research investigation. Simply put, a theory in research methodology refers to the way of making sense of a questionable situation. ${ }^{97}$ Theories represent tentative solutions to problems. A theory is a generalization about a phenomenon, an explanation of how or why something occurs. ${ }^{98}$ Indeed, it is any statements that explain what is measured or described. In fact, any general statements about cause or effect are theory based, at least implicitly. ${ }^{99}$

The theory is a statement of relationships between units observed or approximated in the empirical world. ${ }^{100}$ Academics point out that a theoryis made up of four components. These are definitions of terms or variables; a domain where the theory applies; a set of relationships betweenvariables and accurate predictions. Factual claims and the predictive claims specify whether a particular event could, should or would occur. Hence, the primary function of a theory is to describe, explain, predict or control human phenomena in a variety of contexts. ${ }^{101}$

\section{Knowledge}

A critical literature review enables a researcher the opportunity to paricipate in a written dialogue with other researchers in his area of study. In so doing, the researcher must show that he has really engaged with, understood and responded to the relevant body of knowledge underpinning his research. Here, the underlining word is knowledge.

Knowledge is defined, in legal terms, as awareness or understanding of a fact or circumstance. ${ }^{102}$ It is also a state of mind in which a person has no substantial doubt about the existence of a fact. ${ }^{103}$

A person can be said to have no substantial doubt about the existence of a fact where he perceives that thing with one of the five sense organs. ${ }^{104}$ That is why knowledge is simply defined in Plato's Theaetetus as justified

\footnotetext{
${ }^{94}$ Neumann.

${ }^{95}$ Neumann.

${ }^{96}$ Neumann.

${ }^{97}$ Honors: Communication Capstone, Communication resources, 2000, retrieved 19 March 2015, $<$ http://www.uky.edu/ drlane/capstone/trmdef.htm>.

${ }^{98}$ Honors: Communication Capstone Communication resources.

${ }^{99}$ Honors: Communication Capstone Communication resources.

${ }^{100}$ JG Wacker, 'A definition of theory: research guidelines for different Theory-Building Research Methods in Operations Management', Journal of Operations Management, no. 16, 1998, pp. 361-385.

${ }^{101}$ Honors: Communication Capstone Communication resources.

${ }^{102}$ BA Garner, Black's Law Dictionary, 8th edn, West Group, USA, 2007, p. 888.

${ }^{103}$ Garner.

${ }^{104}$ In biology, the five sense organs are: the eye, nose, tongue, skin and ear. Aristotle (384 BC - 322 BC) is credited with the traditional classification of the five sense organs: sight, smell, taste, touch, and hearing. As far
} 
true belie for true judgment with an account. ${ }^{105}$ This is because true judgment without an account falls outside knowledge. Things, of which there is no account, are not knowable, while those, which have an account, are knowable. Now when a man gets a true judgment about something with an account, his soul is in a state of truth as regards that thing.But he does not know it, for someone who cannot give and take an account of a thing is ignorant about it. ${ }^{106}$ But when he has also got an account of it, he is capable of all this and is made perfect in knowledge. This suggests that knowledge is true judgment with an account based on perception. ${ }^{107}$ The existence of a fact cannot be known without an appended explanation.

Similarly in Theaetetus, ${ }^{108}$ knowledge has been defined as nothing other than perception. ${ }^{109}$ This definition was also compared side by side with what Protagoras used to maintain, for he said, "you know, that man is the measure of all things. Of the things which are, that they are, and of the things which are not, that they are not." Simply put: Knowledge depends on the individual's insight. ${ }^{10}$

Socrates tried to clarify the definition knowledge as perception. This he did by comparing a situation where the wind is blowing, and that one person feels cold while another feels hot. ${ }^{111}$ Or that one feels rather cold, and the other feels very cold. In this respect, Socrates asks a question to the effect: Can one rightly say that, the wind itself, by itself, is cold or not cold? ${ }^{112}$ Or shall we then agree with what Protagoras contended and said it is cold for the one who feels cold, and for the other, not cold? Socrates concludes that things are for the individual such as he perceives them, and perception then is always of what is and unerring as befits knowledge. So it appears, he added. ${ }^{113}$ In this way, Socrates believes that the definition of knowledge is subjective. It depends on a particular individual's ability to perceive things happening around him. Therefore, perception is the key to knowledge.

\section{Research Gap}

As in the above description of the criticalliterature review, gap refers to the missing element in the existing literature. It is the missing element, or gapthat makes a manuscript publishable. ${ }^{114} \mathrm{~A}$ gap in a literature review assists a researcher in three phases. In the formulation of research problem/questions; in the identification of the relevant theories and research studies.And in the later analysis and interpretation of the data. ${ }^{115}$

A research gap is a clear, precise statement of the question or issue that is investigated, with a goal of finding an answer or solution. ${ }^{116}$ Hence, a research gap is an issue or area, identified by the reader's insight, which

back as the 1760 's, the famous philosopher Immanuel Kant proposed that our knowledge of the outside world depends on our modes of perception. Scientific psychic, Anatomy and structure of human sense organs, 2015, retrieved 31 May 2015, <http://www.scientificpsychic.com/workbook/chapter2.htm>.

${ }^{105}$ Theaetetus $200-203 \mathrm{e}$.

${ }^{106}$ Theaetetus 200-203e.

${ }^{107}$ Theaetetus 200-203e.

${ }^{108} 151 \mathrm{~d} 7$-e3.

${ }^{109}$ Theaetetus $150-152 \mathrm{e}$.

${ }^{110}$ Theaetetus $150-152 \mathrm{e}$.

${ }^{111}$ Theaetetus $150-152 \mathrm{e}$.

${ }^{112}$ Theaetetus $150-152 \mathrm{e}$.

${ }^{113}$ Theaetetus $150-152 \mathrm{e}$.

${ }^{114}$ Writing for Publication in Professional Journals, Meaning of a research gap, 2002, retrieved 22 March 2015, $<$ https://msu.edu/course/aec/891/whatisagap.htm>.

${ }_{115}$ Ridley, p. 3.

${ }^{116} \mathrm{Z}$ Mahmud, Handbook of Research Methodology (a Simplified Version), University Publication Centre (UPENA), UiTM, Malaysia, 2009, pp. 1-3. 
warrants research. ${ }^{117}$ Perhaps, this is due to a lack of adequate information, the existence of biased information, or where the right information has not been communicated due to inconsistencies or wrong assumptions. ${ }^{118}$

There are several ways of identifying a research gap, during the reading of the existing literature. When one becomes conversant with topical literature in a particular field, it is then quite easy to find a gap or researchable problem. ${ }^{119}$ Another way of identifying a research gap is by analyzing the needs of others, such as, for example, a sense of dissatisfaction coming from a particular group. ${ }^{120}$ A research gap can emanate from media coverage or listening to stakeholders at public meetings. In this way, the researcher may identify a research gap from current significant press reports.

A research gap can also emanate from research artifacts. The term research artifacts, here refers to the systematic biases, uncontrolled and unintentional, that can threaten the internal or external validity ${ }^{121}$ of one's research conclusions. ${ }^{122}$ Thereby creating a research gap for further inquiry or research. In this way, the research gap is the genesis of the research question, and the critical literature review is the essential element in conceiving the research project.

\section{Literature Search}

Many researchers get ideas for research by reading previous literature, and by thinking of how to extend or refine the previous literature. ${ }^{123} \mathrm{~A}$ researcher cannot perform significant research without first understanding the literature and identifying the gaps in the field. ${ }^{124}$

The literature search is designed to extend understanding of the fundamental concepts, theories and methodologies in the field. ${ }^{125}$ Research using the literature itself as the data for carrying out a study is referred to as 'doctrinal or armchair' or 'library-based' research. ${ }^{126}$ It is common in the field of law, where the literature itself is the focus of the analysis. ${ }^{127}$ All the reports agreed that doctrinal legal research was the most accepted methodology in the discipline of law. ${ }^{128}$

Doctrinal, armchair or library-based research is a form of research that addresses a legal problem or question. In other words, doctrinal research is a form of research methodology that is a library-based study. Where the researcher sits down in a chair in the library and starts the research by locating the materials on the library shelves and archives. The researcher does not need to go outside the library looking for needed materials because they are available in the law library. ${ }^{129}$ Simply put, it is the study of documents in a library. ${ }^{130}$ The aim

${ }^{117}$ Noor, pp. 28-29.

${ }^{118}$ KA Robinson, IJ Saldanha \& NA Mckoy, Framework for identifying research gaps, National Collaborating Centre for Methods and Tools, Hamilton, McMaster University, 2011, retrieved 14 May 2015,

$<$ http://www.nccmt.ca/registry/view/eng/118.html.>.

${ }^{119}$ O'Leary, p. 26.

${ }^{120}$ O'Leary, pp. 40-41.

${ }^{121}$ Internal validity is the approximate truth about inferences regarding cause-effect or causal relationships. Thus, internal validity is only relevant in studies that try to establish a causal relationship. It's not relevant in most observational or descriptive studies while external validity refers to the approximate truth of conclusions the involve generalizations. Put in clear terms, external validity is the degree to which the conclusions in your study would hold for other persons in other places and at other times. Trochim.

${ }^{122}$ DB Strohmetz \& RL Rosnow, 'Artifacts in research process', SAGE Research Method, 2013, pp. 26-28, retrieved 8 June $2015,<$ http://srmo.sagepub.com/view/the-sage-encyclopedia-of-social-science-researchmethods/n24.xml>.

${ }^{123}$ Trochim.

124 Justus, p. 1.

${ }^{125}$ Ridley, p. 30.

${ }^{126}$ The Directory of Open Access Journals (DOAJ) may be of assistance available at $<$ http://www.doaj.org. $>$.

${ }^{127}$ Ridley, p. 33.

${ }^{128}$ T Hutchinson \& N Duncan, 'Defining and describing what we do: Doctrinal legal research', Deakin Law Review, vol. 17, no. 1, 2012, pp. 212-213.

${ }^{129}$ Hutchinson \& Duncan. 
of this kind of study is to review, discover, examine, explain and analyse in a systematic form, facts, principles, provisions, concepts or the functioning of certain laws. The purpose of this form of research methodology is to synthesise and disseminate new knowledge. The kind of data available for this type of research are statutes and cases, (judicial precedent), digests and scholarly treatises.

Most literature searches today are carried out online, using the internet, by electronic means. ${ }^{131}$ Searching literature using the internet is very easy. A researcher is only required to type keywords ${ }^{132}$ of his research area. However, keywords need carefully consideration to select terms that will generate the information being sought. ${ }^{133}$ Vast information relevant to one's area of research will be generated for one to select the most relevant. It is also advisable to use alternative keywords or combination of the words. When searching for literature online, ${ }^{134}$ as this will elicit further information that will help in writing a critical literature review. For example to facilitate this method of literature search some databases use commands called 'Boolean operators.' The most common Boolean operators are 'AND', 'OR' and 'NOT'. 135 'AND' is used whenever one intends to search for articles that include all the identified keywords. ${ }^{136}$ Whereas 'OR' is used whenever one is searching for articles that include any of the identified keywords. 'NOT' is used to exclude articles that contain a specific keyword. ${ }^{137}$

Searching for literature by electronic means requires careful evaluation of sources gathered. ${ }^{138}$ Although search engines such as Wikipedia, ${ }^{139}$ Google, Google Scholar andso on, seem easier to get online information, ${ }^{140}$ they may not be the best sources for finding comprehensive evidence to support one's argument. For example, some sources do not have clearly identified authors or other sources. The implication is that if one cannot identify the author of a book then it is probably unreliable in an academic context. ${ }^{141}$ It is also neccesary to remember that unless a web site is regularly updated, the information on a web site can easily become outdated. ${ }^{142}$ Therefore, the information might not reflect the current position of what the researcher needs. Unregulated sites should be avoided in the course of the search. For example,Wikipedia is a popular source of information online and contains more than 2 million articles. However, the contents can be edited by anyone. Thus, its reliability is an issue. $^{143}$

Journals are regarded as being more up-to-date than books as sources of information. Books can be outdated due to the length of time it takes for publication. However, this does not mean they should be excluded as they are an acceptable and valuable source of information. ${ }^{144}$ Still, a researcher is also expected to explore questioning and analytical approach in the course of the literature search. The questioning and analytical approach can take the form of asking the author's central argument or the author's conclusions, and comparing and constrasting them with the various scholarly arguments. One can also question the evidence put forward in support of the

\footnotetext{
${ }^{130}$ Neumann.

131 Bolderston.

${ }^{132}$ Keywords are words used to find relevant and useful material during the search. The keywords chosen for the search are important, as they are "The cornerstone of an effective search". F Timmins \& C McCabe, 'How to conduct an effective literature search', Nurs Standard, vol. 20, 2005, pp 41-47.

${ }^{133}$ Patricia, Ryan \& Coughlan.

${ }^{134}$ Patricia, Ryan \& Coughlan.

${ }^{135}$ C Ely \& I Scott, 'Essential study skills for Nursing', Elsevier, Edinburgh, 2007, pp 1-223.

${ }^{136}$ Patricia, Ryan \& Coughlan.

${ }^{137}$ Patricia, Ryan \& Coughlan.

${ }^{138}$ JM Mcgrath \& HA Samra, 'Before you search the literature: how to prepare and get the most out of citation databases', Newborn \& Infant Nursing Reviews, vol. 12, no. 3, 2012, pp. 162-170.

${ }^{139}$ Wikipedia Main Page, retrieved 10 June 2015, < http://en.wikipedia.org/wiki/main_Page $>$.

${ }^{140}$ Mcgrath \& Samra.

${ }^{141}$ Ridley, p. 63.

142 Ridley, p. 63.

${ }^{143}$ Bolderston, pp. 86-92, 88.

${ }^{144}$ Patricia, Ryan \& Coughlan.
} 
author's arguments. But author's conclusions must be fully identified and analyzed with strong contextual evidence. $^{145}$

Taking all these components together, they can be summarized one after another as follows. A thesis is a form of argument that presents relevant information and a refutation. It is in a classical form and has been for thousands of years. It is the necessary precursor to proposing a law. Research is the gathering of data in a stated context. The theory describes human phenomena in a specified context. Knowledge is a subjective perception and awareness. A research gap is an issue identified by the reader's insight, where the right information has not been communicated. A literature search is a search for evidence, planned to sustain an argument. Thus, the critical literature review sets a context for research and fills the research gaps with new perception and awareness of a cogent argument.

\section{Format of a Critical Literature Review}

This section critically examines the scholarship on the best formats for a legal critical literature review, so that argument can determine a consistent form of outcome in every critical literature review. Each part is designed to achieve a particular purpose in the light of the existing literature. The cumulative effect of this exercise is to show how a critical literature review can be used to identify research gaps, in a specified context.

The typical form of the critical literature review in a thesis consists of three chapters. The first chapter explores theories, the second establishes a theoretical framework, and finally, a section outlining the historical context of the research. ${ }^{146}$ However, a good literature review would be employed when the thesis consists of some different research studies. In this format, the critical literature review might begin with an introduction, and continue at the commencement of each of the various major parts of the thesis. These reviews, prefixing the individual studies, are written to amplify in finer detail what the researcher presented in the introduction. ${ }^{147} \mathrm{At}$ the beginning of the critical literature review.The researcher should state the purposes of the literature review, the historical background and contemporary context of the area of the research, as well as the theories and concepts,identified. Then should come a statement of its delimitations, (by virtue of the gaps), and finally state the significance of the issue being researched. ${ }^{148}$

The research will undoubtedly be situated within a historical context, the last phase of which is the contemporary context, comprising debate in the field and recent and ongoing research. It is this contemporary context that will link very closely to a discussion of the significance and justification of the subject research work. ${ }^{149} \mathrm{~A}$ gap in previous research can be used to justify one's work, ${ }^{150}$ where the researcher was able to address the research problem of his study. In fact, this is the only way a research work would become original and thus contributes to the body of knowledge. Also, it is essential to incorporate citations in an argument form from the literature in the field, which support the claim that the researcher has addressed the problem under investigation. ${ }^{151}$

In fact, every research project must answer a question or identify gap in the literature. This research question starts with a broad idea of interest, which is the initial problem that the researcher wishes to study. The idea is normally subjected to brainstorming, brain-writing or concept mapping. ${ }^{152}$ The researcher should also subject the research question to evaluation as to whether the question will yield an interesting answer.

The critical literature review includes the formulation of a research topic and research questions. Formulating a research topic is sometimes difficult. Many researchers get ideas for their research topics by reading the

${ }^{145}$ Ridley, p. 48.

${ }^{146}$ Ridley, p. 5.

${ }^{147}$ Ridley, p. 11.

${ }_{148}$ Ridley, p. 25.

${ }^{149}$ Ridley, p. 19.

${ }^{150}$ Ridley, p. 24.

${ }^{151}$ Ridley, p. 25.

${ }^{152}$ Trochim. 
literature and thinking how to extend or refine previous research. ${ }^{153}$ Where a researcher formulates a topic, the next task is to articulate the research questions. A researcher should not reject a question because someone has already asked it. He should pursue its answer as if asked first. Even whenthe researcher reaches a conclusion with certainty that someone has answered it, he should not be discouraged.As hemight come up with a better answer or at least one with a new slant. ${ }^{154}$ In the humanities and social sciences the best questions usually have more than one right answer.

There are four common types of research questions, in a given research study. And the type of question has critical implications for the appropriate research design. The first one is a descriptive question that asks about the characteristics of something. Examples of descriptive questions include: What is the average math achievement of the nation's fourth graders? What is the career satisfaction of District of Columbia (DC) computer industry professional employees?

The second type is called associational questions, which ask about categorical differences or correlations of certain things. An example of associational questions includes: How does the math achievement of the nation's fourth-grade Hispanic youth compare with that of the nation's fourth-grade African-American youth? Is DC computer industry professional employees more or less satisfied with their careers than are DC media industry professional employees?

The third type is called a causal question, which asks about what causes observed differences or changes. For example: What accounts for the wide variation in math achievement among fourth-grade Hispanic youth? Will two hours a week of Math Explosion exercises over a semester raise the math achievement of low-achieving fourth-grade Hispanic youth?

The last one is called the benefit-cost question, which asks about whether the benefits of a given intervention are worth more than the costs. For example: Do the benefits of Math Buster exercises exceed the costs of the computer laboratory, software, and laboratory supervision? Is the benefit/cost ratio of Math Explosion exercises greater than the benefit/cost rate of after school tutoring by the teachers? In the end, the review should conclude with a concise summary of the findings that describes the current knowledge and offer a rational for further research. ${ }^{155}$ In a view which necessitates the proposed research, perhaps due to any gaps identified in the knowledge. ${ }^{156}$ The review should provide recommendations for and implications of the proposed research. ${ }^{157}$

Thus, a critical literature review aids in answering research questions. It covers everything relevant that is written on a topic: books, journal articles, newspaper articles, historical records, government reports, theses, and dissertations. The important word is "relevant", ${ }^{158}$ which could include a piece of case law as a form of literature.

Generally speaking, a reasonable number of bibliographic references in a literature review varies by the targetted degree. For example, the undergraduate review should consist of 5-20 titles. The honours dissertation should consist of about 20 plus titles, and a Masters thesis 40 plus titles while a review for a doctoral thesis ought to have more than 50 titles. $^{159}$

There are so many reasons why critical literature reviewsare required in academic writing. It assists in eliciting information ${ }^{160}$ for answering research questions. A thorough literature review assists in identifying and delimiting the research problem. In fact, the literature review is a tool for seeking new lines of inquiry or avoiding fruitless approaches, as in conducting research on an issue that has been carried out previously by

${ }^{153}$ Trochim.

${ }^{154}$ KL Turabian, A manual for writers of research papers, theses and dissertations, $7^{\text {th }}$ edn, the University of Chicago Press, London, 2007, pp. 18-19.

${ }^{155}$ Patricia, Ryan \& Coughlan, p. 43.

${ }^{156}$ Patricia, Ryan \& Coughlan, p. 43.

${ }^{157}$ Patricia, Ryan \& Coughlan, p. 48.

${ }^{158}$ University of Canberra, Writing a literature review, retrieved 24 March 2015, $<\mathrm{http}$ //www.canberra.edu.au/studyskills/writing/literature\#What\#What $>$.

${ }^{159}$ University of Canberra.

${ }^{160}$ Patricia, Ryan \& Coughlan, p. 38. 
another author. ${ }^{161}$ The critical literature review consists of some chapters, each with its purpose, the outcome of whose argument is to formulate the research question, a thesis statement and research objectives.

\section{Writing the Literature Review}

Having explained the format of a critical literature review, in terms of a consistent outcome, this section critically examines some required skills for the writing of an effective literature review. Once the appraisal of the literature is completed, consideration must be given to how the review will be structured and written. ${ }^{162}$ This is because good structuring is essential to enhance the flow and readability of the review. ${ }^{163}$ Primarily, the review should include an introduction, ${ }^{164}$ body ${ }^{165}$ and conclusion. ${ }^{166}$ A researcher should start writing as early as possible. Even before finalizing the plan or outline of the literature review. He should attend to questions about thedepth of knowledge of the research topic, or the great debates in the field. ${ }^{167}$

The introduuctory part of a critical literature review shouldprovide the significane and purpose of the research. It should contain a section spcifically outlining the qusestion or problemthat the research intends to answer or solve. Here the researcher must show that there is a particular problem in a given research area. And that it is nececessary to address the problem.

Another section of the literature review must provide a clear, precise thesis statement as this will help a researcher unify the research. This will also guide many decisions about what details to keep and what to discard. The outline of the entire research document must also be provided including the methodology intended to be employed for the research.

If the review is a significant work, such as for a Ph.D. thesis, summaries should be interspersed throughout the chapter. ${ }^{168}$ Themethod is the nature of the architecture of the critical literature review. The principle of creating an appropriatestructure for the literature review may be stated as follows.

The underpinning principle of this process is that you put together an argument and draw on your source texts to provide support for your assertions. By developing your argument, you show that you are using the literature for your purposes, rather than being controlled by the authors whose work you have read and are citing in your writing. The process involves devising an outline of your argument steps when then form the basis of the architecture of your review. For each step of your argument, group together the sources that contribute to or provide support for yourassertion.

${ }^{161}$ TJ Sullivan, Methods of Social Research, Orlando FI, Prentice Hall, 2001, pp 92-93 cited in U Sekan, Research methods in business studies: a skill building approach, 2nd edn, John Wiley \& Sons Inc., New York, 1992, pp. 39-40.

${ }^{162}$ Patricia, Ryan \& Coughlan, p. 38.

${ }^{163} \mathrm{~J}$ Colling, 'Demystrifying the Clinical Nursing research process: the literature review', Urol Nurs, vol. 23, no. 4, 2003, pp. 297-299.

${ }^{164}$ The introduction should include the purpose of the review and a brief overview of the problem under investigationa. Patricia, Ryan \& Coughlan, p. 42.

${ }^{165}$ The main body of the thesis or report presents and discusses the findings from the literature. Here, the reader should know that the review has understood and synthesized the relevant information of the research, rather than merely describing what other authors have found. As the role of the researcher is to summarize and evaluate evidence about a topic, pointing out similarities and differences and offering possible explanations for any inconsistencies uncovered. DF Polit \& CT Beck, Nursing research: principles and methods, 7th edn, 2006, Lippincott, Williams \& Wilkins, Philadelphia, 2004, pp. 1-30.

${ }^{166}$ The Conclusion should conclude with a concise summary of the findings that describes current knowledge and offer a rationale for conducting future research. N Burns \& SK Groove, Understanding nursing researchbuilding an evidence based practice, 4th edn, St. Louis, Saunders Elsevier, 2007, pp. 1-15.

${ }^{167}$ Ridley, p. 81.

${ }^{168}$ Ridley, p. 82. 
From the argument steps that you devise, you can then develop the headings and subheadings that become the framework for your review. ${ }^{169}$

The introduction should be about $10 \%$ of the whole thesis, and the literature review ought to be about $20 \% .{ }^{170}$ An efficient researcher writes a summary and critique of each text read, and then uses these critiques when starting the analytic process of the literature review. In this way, he should selectively take the points from the related literature providing support for his claims and assertions. ${ }^{171}$

There are strategies for achieving a critical approach to the writing of the critical literature review. These include comparing and contrasting different theories, concepts, arguments and terminologies from the related literature. And also indicating the position on the research. This should be dones throunghout the chapters of the research work.

Other means of achieving a critical approach to writing a critical literature review also include agreeing with, confirming or defending a finding or point of view through an analysis of its merits and limitations. The author might also concede that an existing point of view has some strengths but qualifying your support of the position by highlighting certain weaknesses. The author might reject a point of view and giving reasons for the rejection; for example inadequacy and lack of evidence, fallaciesin the argument or research. ${ }^{172}$ Fallacies here refer to an error in reasoning, usually based on mistaken assumptions. ${ }^{173}$

A fallacy is a violation of one of the criteria for a good argument. ${ }^{174}$ Any argument that is in some way short of a good argument is a poor or fallacious one. A poor argument argument is one that is made without a cogent or sufficient evidence to substantiate a particular proposition. Still, an argument is poor where it fails to provide an effective rebuttal to the most serious challenges in the literature under review or to the argument itself. Hence, it is unreliable in an academic context. However, it can open a gate for yet another piece of academic research.

Understanding the notion of fallacy helps one not only to recognize a poor argument but also to know what a good argument should look like. A fallacy, then, is much more than something to avoid in argumentation. ${ }^{175}$ It is not just one of those things on a list of things that one should not do as a researcher. A fallacy is so conceived that if an argument exhibits a fallacy, it is probably a bad one, but if the argument exhibits no such violation, it is a good argument. ${ }^{176}$

Fallacious arguments come from the notion of deception. ${ }^{177}$ Fallacious arguments usually have the deceptive appearance of being good arguments. Thismight explain why they can be so misleading. Such deceptiveness, of course, may be unintentional on the part of the arguer. ${ }^{178}$ But it does not matter whether the mistake was intended or not; a mistake is a mistake, regardless of the arguer's intention. Hence, in the literature review is in all respect critical if fallacious arguments are avoided as much as possible. ${ }^{179}$

\footnotetext{
${ }^{169}$ Ridley, p. 85.

${ }^{170}$ Ridley, p. 88.

${ }^{171}$ Ridley, p. 118.

172 Trochim.

${ }^{173}$ TE Damer, Attacking Faulty Reasoning,A practical guide to Fallacy-Free Arguments, 4th edn, Wadsworth/Thomson Learning, Belmont, USA, 2001, pp. 42-50.

${ }^{174}$ Arguments here means the exertion of effort to support certain views with reasons to support conclusions. Argument is essential to a critical literature review, because it is a way of finding out which views are better than others. Not all views are equal. Some conclusions can be supported by good reasons. Others have much weaker support. But often we do not know which are which. We need to give arguments for different conclusions and then assess those arguments to see how strong they really are. A Weston, A rulebook for arguments, 4th edn, Hackett Publishing Company, Indianapolis, Cambridge, 2009, pp. xi-xiv.

${ }^{175}$ Weston.

${ }^{176}$ Weston.

${ }^{177}$ G Bassham, W Irwin, H Nardone \& JM Wallace, Critical thinking: a students' introduction, 3th edn, McGraw-Hill Companies, New York, 2008, pp. 124-170.

${ }^{178}$ Damer.

${ }^{179}$ Damer.
} 
There are many types of fallacies in academic writing,such as the ecological and exceptional fallacies ${ }^{180}$ and the fallacy of the undistributed middle. ${ }^{181}$ The ecological fallacy involves a situation where one makes assumption or conclusion about an individual based only on analysis of a group data. The exceptional fallacy involves a situation where one reaches a group conclusion on the basis of exceptional cases. ${ }^{182}$

Schuyler wrote that the fallacy of the undistributed middle was a logical fallacy occurring in syllogisms. For example: All P is M, All S is M, therefore all S is P. The fallacy of the undistributed middle consists in the fact that only a part of the middle is compared with the extremes in the two premises, and it is not certain that it is the same part. The extremesare not compared with the same thing, and there is no reason for inferring their relations to each other. ${ }^{183}$

The critical literature review consists of some chapters, each with its purpose, the outcome of whose argument is to formulate the research question, a thesis statement and research objectives.

\section{Conclusion}

A legal critical literature review's components can be summarized one by one as follows. A thesis is a form of argument that presents relevant information and a refutation. It is in a classical form and has been for thousands of years. It is the necessary precursor to proposing a law. Research is the gathering of data in a stated context. The theory describes human phenomena in a specified context. Knowledge is a subjective perception and awareness. A research gap is an issue identified by the reader's insight, where the right information has not been communicated. A literaturesearch is a search for evidence, planned to sustain an argument. Thus, the critical literature review sets a context for research and fills the research gaps with new perception and awareness of a cogent argument. The critical literature review consists of some chapters, each with its purpose, the outcome of whose argument is to formulate the research question, a thesis statement and research objectives. The legal critical literature review will be maximally effective when it sets a context for research, identifies fallacies in the scholarship in order to discover research gaps, and then moulds this outcome into a research question, a thesis statement and research objectives.

\section{Bibliography}

[1] Bailey, DRS, The Lesser Declamations, vol. 1, Harvard University Press, England, 2006.

[2] Bassham, G, W Irwin, H Nardone \& JM Wallace, Critical Thinking: A Students' Introduction, 3th edn, McGraw-Hill Companies, New York, 2008.

[3] Bolderston, A, 'Writing an Effective Literature Review', Journal of Medical Imaging and Radiation Sciences, vol. 39, 2008.

[4] Colling, J, 'Demystrifying the Clinical Nursing research process: the literature review', Urol Nurs, vol. 23, no. 4, 2003, pp. 297-299.

[5] Cooper, JM \& DS Hutchinson, Plato complete works, Hackett Publishing Co., Indiana, 1997.

[6] Corbett, EPJ \&RJ Connors, Classical Rhetoric for the modern students, 4th edn, Oxford University Press New York, 1999.

[7] D'Angelo, FJ, Composition in the classical tradition, Allyn \& Bacon, USA, 2000.

\footnotetext{
180 Trochim.

${ }^{181}$ A Schuyler, The Principles of Logic, American Book Company, USA, 1869, pp. 50-53.

182 Trochim.

183 Schuyler.
} 
Md. Nuruddeen, 'The Legal Critical Literature Review', UUMJLS, vol. 6, no. 1, 2015, pp. 013-032.

[8] Damer, TE, Attacking faulty Reasoning, apractical guide to Fallacy-Free Arguments, 4th edn, Wadsworth/Thomson Learning, Belmont, USA, 2001.

[9] Ely, C \&I Scott, ‘Essential Study Skills for Nursing',Elsevier, Edinburgh, 2007.

[10] Fink, A, Conducting research literature reviews: from the internet to paper, 2nd edn, Sage

Publications, Thousand Oaks, Canada, 2004, pp. 20.

[11] Garner, BA, Black's Law Dictionary, 8th edn, West Group, USA, 2007.

[12] Hart, C, Doing a literature review, Sage Publications, London, 1998.

[13] Hodges, JC, ST Web \&RK Miller, Harbrace College handbook, 12th edn, Harcourt Brace College Publishers, USA, 1994.

[14] Honors: Communication Capstone,Communication resources, 2000, retrieved 19 March2015,<http://www.uky.edu/ drlane/capstone/trmdef.htm>.

[15] Hutchinson, T \& N Duncan, 'Defining and describing what we do: Doctrinal Legal Research', Deakin Law Review, vol. 17, no. 1, 2012.

[16] Justus, RJ, 'A guide to writing the dissertation literature review,' Practical Assessment, Research and Evaluation, vol. 14, no. 13, June 2009.

[17] Kennedy, GA, Progymnasmata - Greek textbooks of Prose Composition and Rhetoric, Society of Biblical Literature, Atlanta, USA, 2003.

[18] LaRocque, P, 'Vague Qualifiers' - A commentary,KERA News, 2015,retrieved 9

June2015, <http://keranews.org/post/vague-qualifiers-commentary $>$.

[19] Lynn, SC \& R Ronald, Basic research methods for Librarians, 5th edn, Greenwood Publishing Group, USA, 2010.

[20] Mahmud, Z, Handbook of Research Methodology (a Simplified Version), University Publication Centre (UPENA), UiTM, Malaysia, 2009.

[21] Mcgrath, JM \& HA Samra, 'Before you search the literature: how to prepare and get the most out of citation databases', Newborn \& Infant Nursing Reviews, vol. 12, no. 3, 2012.

[22] Nervegna, S, Menander in Antiquity: The contexts of reception, Cambridge University Press, 2013.

[23] Neuman, WL, Social research methods: qualitative and quantitative approaches, 5th edn, Pearson Education Inc., Boston, 2003.

[24] Neumann, R, 'Research and scholarship: perceptions of Senior Academic Administrators', Higher Education, vol. 25, no. 2 Mar., 1993.

[25] Noor, NM, Writing research \& thesis proposals: guidelines \&examples, Penerbit Press, Malaysia, 2012.

[26] Nuruddeen, M, 'Legal and human rights issues in Freedom of Information Act 2011', Human Rights Review, vol. 2, 2012, pp. 171-190.

[27] O'Leary, Z, Researching real-world problems: a guide to methods inquiry, Sage Publications Ltd., London, 2005. 
Md. Nuruddeen, 'The Legal Critical Literature Review', UUMJLS, vol. 6, no. 1, 2015, pp. 013-032.

Ogden, CK, Bentham's Theory of Fictions, Routledge, New York, 2001.

[29] Patricia, C,Ryan F \&Coughlan M, 'Undertaking a literature review: a step-by-step approach', British Journal of Nursing, vol. 17, no. 1, 2008.

[30] Polit, DF \& CT Beck, Nursing research: principles and methods, 7th edn, 2006, Lippincott, Williams $\&$ Wilkins, Philadelphia, 2004, pp. 1-30.

[31] Poel, MV, 'The Latin Declamation in Renaissance Humanism', The Sixteenth Century Journal, vol. 20 no. 3, 1989.

[32] Richard,N, What are Progymnasmata? Classical Rhetorical exercises for today's writers, About Education, 2015, retrieved 28

March2015,<http://grammar.about.com/od/qaaboutrhetoric/f/fqprogymnasmata.htm>.

[33] Richard, N, Thesis (composition), About Education, 2015, retrieved 22 March 2015, $<$ http://grammar.about.com/od/tz/g/thesis.htm>.

[34] Ridley, D, The literature review-astep-by-step guide for students, Sage, London, 2008.

[35] Robinson, KA, IJ Saldanha \& NA Mckoy, Framework for identifying research gaps, National Collaborating Centre for Methods and Tools, Hamilton, McMaster University, 2011, retrieved 14 May 2015, $<$ http://www.nccmt.ca/registry/view/eng/118.html.>.

[36] Schuyler, A, the Principles of logic, American Book Company, USA, 1869.

[37] Scientific Psychic, Anatomy and structure of human sense organs, 2015, retrieved 31May2015, $<$ http://www.scientificpsychic.com/workbook/chapter2.htm>.

[38] Strohmetz, DB\& RL Rosnow, 'Artifacts in research process', SAGE Research Method, 2013, pp. 2628 , retrieved 8 June2015, <http://srmo.sagepub.com/view/the-sage-encyclopedia-of-social-science-researchmethods/n24.xml $>$.

[39] Steward, B, 'Writing a literature review', Br J Occup Ther 67, 2004, pp. 495-500.

[40] Sullivan, TJ, Methods of social research, Orlando FI, Prentice Hall, 2001, pp 92-93, in U Sekan (2nd ed.), Research methods in business studies: askill building approach,John Wiley \& Sons Inc., New York, 1992, pp. 39-40.

[41] The Directory of Open Access Journals (DOAJ), 2015, retrieved 31 May 2015, $<$ http://www.doaj.org.>.

[42] Theaetetus

[43] Timmins, F\& C McCabe, 'How to conduct an effective literature search', Nurs Standard, vol. 20, 2005, pp. 41-47.

[44] Trochim, WM, 'Foundations', Research Methods Knowledge Base, 2006, retrieved 24 March2015, $<$ http://www.socialresearchmethods.net/kb/intres.php $>$.

[45] Turabian, KL, A manual for writers of research papers, theses and dissertations, 7 thedn, the University of Chicago Press, London, 2007.

[46] The University of Canberra, Writing a literature review, retrieved 24 March 2014,<http://www.canberra.edu.au/studyskills/writing/literature\#What\#What>.

[47] Wacker, JG, 'A Definition of theory: research guidelines for different Theory-Building Research Methods in Operations Management', Journal of Operations Management, no. 16, 1998. 
Md. Nuruddeen, 'The Legal Critical Literature Review', UUMJLS, vol. 6, no. 1, 2015, pp. 013-032.

[48] Webster, J \&RT Watson, 'Analyzing the past to prepare for the future: writing a literature review', MIS Quarterly, vol. 26, no. 2, June 2002.

[49] Western Illinois, University guidelines for the structure and format of a thesis or applied project, Department of Geography, 2012, retrieved 29

March2015,<http://www.wiu.edu/cas/geography/thesis/thesis_guidelines.pdf $>$.

[50] Weston, A, A rulebook for Arguments, 4th edn, Hackett Publishing Company, Indianapolis, Cambridge, 2009.

[51] Writing for Publication in Professional Journals, Meaning of a research gap, 2002, retrieved 22 March2015, <https://msu.edu/course/aec/891/whatisagap.htm>. 